para os rebuçados Halls ${ }^{\circledR}$ sabores cítricos sem açúcar (Mondelez Portugal). Conclusões: O consumo frequente de produtos com baixo $\mathrm{pH}$ e valores de acidez titulável mais elevados parecem determinantes na predisposição e evolução da erosão, apesar da influência de outros fatores (tipos de ácidos presentes, adesividade, efeito quelante, teor de fosfatos, fluoretos, cálcio e capacidade tampão salivar). Os componentes testados apresentaram $\mathrm{pH}$ inferior ao $\mathrm{pH}$ considerado crítico para o esmalte e valores elevados de acidez titulável, podendo contribuir para o risco de erosão em dentição decídua, tendencialmente prenunciando a ocorrência na permanente, tornando crucial o diagnóstico precoce e a implementação de medidas preventivas. http://doi.org/10.24873/j.rpemd.2019.12.616

\section{\#159 Ansiedade em Odontopediatria: contributo para validação do CFSS-DS na população portuguesa}

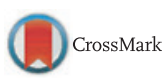

Alina Spinache *, Ana Luisa Costa, Teresa Xavier, Sara Rosa, Francisco Caramelo

Área de Medicina Dentária, Faculdade de Medicina, Universidade de Coimbra

Objetivos: Experiências de medo e ansiedade relacionados com tratamentos dentários são comuns, continuando a ser uma das principais limitações na colaboração e execução com sucesso dos procedimentos clínicos em Odontopediatria. A sua mensuração através de instrumentos válidos, de que é exemplo o Children's Fear Survey Schedule-Dental Subscale, é essencial para adequação e otimização desses mesmos tratamentos. Com este trabalho pretendeu-se testar e avaliar algumas características psicométricas básicas deste questionário, um dos mais aceites referentes a este tópico, contribuindo para a validação (português, Portugal) e consubstanciação da sua utilização futura. Materiais e métodos: A amostra compreendeu 71 crianças, de idades compreendidas entre os 7-10 anos, consultadas em Odontopediatria e selecionadas cumprindo critérios de inclusão definidos, as quais responderam, faseadamente, às 15 questões do questionário, antes e após tratamento, tendo por base uma versão criteriosamente traduzida e adaptada para português (Portugal) a partir da versão traduzida de português (Brasil). Os dados obtidos foram inseridos em Microsoft Excel ${ }^{\circledR} 2010$ e a posterior análise estatística permitiu testar preliminarmente a fiabilidade e validade desta escala. Foi realizada uma análise de comparação entre as respostas antes e depois da consulta, usado o coeficiente iota para avaliar a concordância entre os dois momentos e calculada a percentagem de respostas em que houve alteração. Na avaliação do instrumento realizou-se uma análise fatorial exploratória para os dados antes da consulta; com base nesta informação calcularam-se pontuações para cada um dos constructos encontrados e uma pontuação global de ansiedade para as crianças participantes. Resultados: Dos resultados salienta-se que a análise fatorial exploratória permitiu avaliar os constructos medidos e quais as questões contributivas para estes. Percebeu-se ainda que o facto de existirem dois momentos distintos de aplicação do questionário permitiu obter valores de discordância entre as respostas referentes a esses dois momentos. Conclusões: A análise conduzida permi- tiu determinar um conceito bidimensional da presença de ansiedade e medo nos participantes verificando-se que, apesar deste questionário ser amplamente aceite e validado em diversos países, poderá beneficiar de reformulação de alguns itens, objetivando a obtenção dum modelo culturalmente válido para aplicação específica na população portuguesa. http://doi.org/10.24873/j.rpemd.2019.12.617

\section{\#160 Comparação da posição condilar com registos em Relação Centrica e em Posição de Referência}

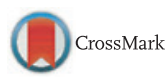

Marta Abreu Ferreira*, Pedro Mariano Pereira, Hélder Nunes Costa, Luís Proença

Instituto Universitário Egas Moniz

Objetivos: Verificar a existência de diferenças na posição condilar entre o registo intermaxilar em Relação Centrica e o registo intermaxilar na Posição de Referência. Materiais e métodos: Foi realizada a montagem em articulador dos modelos de estudo de 20 indivíduos e realizados registos intermaxilares em Relação Centrica e em Posição de Referência, através das técnicas de manipulação bimanual e chinpoint guidance, respetivamente. Foi obtida a relação da maxila com o crânio de cada indivíduo recorrendo ao arco facial e, através do elemento Condylar Position Measurement do articulador, foram registadas as posições condilares em Relação Centrica e em Posição de Referência nos três planos do espaço. Após terem sido obtidos os registos, foi utilizado o programa informático NemoCeph, para medir a diferença das posições condilares. Foram comparadas as diferenças da posição condilar entre os registos intermaxilares em cada um dos planos do espaço, em cada côndilo, através do teste t-student. Considerou-se um nível de significância de $5 \%(p<0,05)$. Resultados: Apenas se verificaram diferenças estatisticamente significativas entre a posição condilar na Posição de Referência e em Relação Centrica, no plano sagital no côndilo direito $(p=0,013)$, estando o côndilo localizado mais para posterior no registo em Relação Centrica, em relação ao registo em Posição de Referência. Nos outros planos do espaço, não foram encontradas diferenças estatisticamente significativas na posição condilar. Conclusões: Apesar das diferenças verificadas no plano sagital no côndilo direito, os resultados obtidos são indicadores de que é semelhante realizar o registo intermaxilar em Relação Centrica ou em Posição de Referência, estando esta escolha dependente da opinião e experiência do clínico.

http://doi.org/10.24873/j.rpemd.2019.12.618

\#161 Avaliação da presença de dor muscular e articular em idosos institucionalizados

Joana Maria Figueiredo Ferreira dos Santos*, Sarah Goolamhussen, Patrícia Fonseca, Nélio Veiga

Universidade Católica Portuguesa - Instituto de Ciência da Saúde de Viseu

Objetivos: O envelhecimento humano é caracterizado por um decréscimo gradual da capacidade de remodelação adap- 